\title{
MIDAS
}

Museus e estudos interdisciplinares

$3 \mid 2014$

Varia e dossier temático: "Museos y participación biográfica"

\section{O projeto Picar o Ponto: Memórias orais de operários da Fábrica Robinson}

Picar o ponto project: Oral memories of the Robinson factory workers

\section{Célia Gonçalves Tavares e Roberto Leite}

\author{
C OpenEdition \\ Journals \\ Edição electrónica \\ URL: http://journals.openedition.org/midas/531 \\ DOI: $10.4000 /$ midas.531 \\ ISSN: 2182-9543 \\ Editora: \\ Alice Semedo, Paulo Simões Rodrigues, Pedro Casaleiro, Raquel Henriques da Silva, Ana Carvalho \\ Refêrencia eletrónica \\ Célia Gonçalves Tavares e Roberto Leite, «O projeto Picar o Ponto: Memórias orais de operários da \\ Fábrica Robinson », MIDAS [Online], $3 \mid$ 2014, posto online no dia 09 junho 2014, consultado no dia 19 \\ abril 2019. URL : http://journals.openedition.org/midas/531 ; DOI : 10.4000/midas.531
}

Este documento foi criado de forma automática no dia 19 Abril 2019.

\section{cc) (†)}

Midas is licensed under a Creative Commons Attribution-NonCommercial-ShareAlike 3.0 International License 


\title{
O projeto Picar o Ponto: Memórias orais de operários da Fábrica Robinson
}

Picar o ponto project: Oral memories of the Robinson factory workers

\author{
Célia Gonçalves Tavares e Roberto Leite
}

\section{Introdução}

1 Na condução do projeto para o espaço Robinson, em Portalegre, tem-se procurado integrar um corpus museal, pensando na necessária ligação entre dois lugares distintos (o convento do século XIII, a fábrica do século XIX) e o seu destino comum: o Museu Robinson. Trabalho complexo e exigente na medida que se constrói no domínio do simbólico, do histórico e do patrimonial das memórias que habitam todo o complexo classificado como Conjunto de Interesse Público, desde dezembro de 2012 (Portaria n.․․ 740), requerendo o cuidado para respeitar a integridade e a expressão das referências e preexistências significativas. Procura-se, assim, com a reutilização do convento e da fábrica reabilitar o património histórico, arquitetónico e industrial, valorizando a sua relação com Portalegre, ao interpretar e divulgar a sua evolução e ao potenciar a formação e fruição de novos públicos.

2 Tutelado pela Fundação Robinson ${ }^{1}$, o museu é constituído por dois núcleos: o núcleo da Igreja do Convento de São Francisco e o núcleo da Fábrica Robinson ${ }^{2}$. No projeto de musealização da Fábrica Robinson (Plano de Intervenção Histórica e Museológica do Espaço Robinson) foi reservada uma alínea para a Promoção de Estudos da Envolvente Histórica, Antropológica e Etnográfica, o que reflete os objetivos do programa nas suas linhas de investigação científica multidisciplinar.

3 As práticas de pesquisa desenharam-se em frentes distintas. Uma primeira fase visou a perceção da constituição da rede de fixação da família Robinson e o conhecimento da indústria familiar (em Halifax e Portalegre), completada com o laborioso trabalho de 
inventário do património industrial da fábrica. Num primeiro momento procurou-se captar as dimensões humanas e o facto de haver um operariado efetivo e disponível, com os seus saberes e memórias, levou a que se trabalhasse a partir da recolha oral antropológica.

Considerando a investigação antropológica enquanto projeto e processo procurou-se nessa aproximação aos operários da Fábrica Robinson observar no terreno com o objetivo de compreender o espaço fábrica na sua dimensão humana. Tendo em conta as premissas do conhecimento antropológico, que procede de culturas e grupos humanos vivos e não de laboratórios (Burgess 1997, 11), privilegiou-se na investigação a abordagem às vivências, às experiências, ao quotidiano das pessoas e os seus significados.

Integrado na Rede de Património de Portalegre, Edificado, Móvel e Imaterial (2008), o projeto Antigos Habitantes incluiu a recolha oral como ferramenta necessária à fixação e salvaguarda da memória patrimonial imaterial que se reporta à fábrica. Todo um trabalho de registo, de cariz antropológico, da memória do trabalho, do saber-fazer, um percurso pelo quotidiano de bulício industrial, testemunhos de vivências que permitirá construir um painel de histórias de vida que se confundem com a história da fábrica. Assumindo que:

[...] o património industrial reveste um valor social como parte do registo de vida dos homens e mulheres comuns e, como tal, confere-lhes um importante sentimento identitário (...); estes valores intrínsecos aos próprios sítios industriais, às suas estruturas, aos seus elementos constitutivos, à sua maquinaria, à sua paisagem industrial, à sua documentação e também aos registos intangíveis contidos na memória dos homens e das suas tradições. (TICCIH 2003)

6 Assim sendo, pretende-se com a apresentação da iniciativa de programação Picar o Ponto avaliar o contributo dos operários, enquanto protagonistas, para o processo de musealização da Fábrica Robinson. Essa importância, contemplada também na Convenção da Salvaguarda do Património Cultural Imaterial (2003) da UNESCO dá conta da dinâmica entre o indivíduo (o operário), enquanto protagonista da sua história/memória e intérprete do seu património cultural, e o objeto patrimonial (a fábrica):

[...] entende-se por "património cultural imaterial" as práticas, representações, expressões, conhecimentos e técnicas - junto com os instrumentos, objetos, artefactos e lugares culturais que lhes são associados - que as comunidades, os grupos e, em alguns casos, os indivíduos reconhecem como parte integrante de seu património cultural. (UNESCO 2003)

7 Nesta definição de património cultural imaterial, cujas premissas subscrevemos, destacamos a singularidade e o caráter individual intrínseco na sua transmissão. Acresce a esta intenção demonstrar a importância da iniciativa enquanto estratégia que contribui para o envolvimento da comunidade local na construção e definição do núcleo da Fábrica Robinson do Museu Robinson. No campo da museologia industrial, Filipe (2001, 155) enfatiza o papel dos museus na identificação de estratégias «de intervenção que contribuam para o desenvolvimento sustentável, passando pela reflexão sobre a relação entre a desindustrialização e as políticas de constituição de acervos (ou seja, de recursos endógenos daquele desenvolvimento), sua incorporação e tratamento museológico, na perspetiva duma apreensão pelos públicos». 


\section{Os Robinson e o operariado}

«Qual é o número de operários? homens, mulheres, e menores de ambos os sexos?» (Inquérito Industrial

1881, 63) crescimento considerável, que se traduziu, por exemplo, no aumento do número de habitantes que passou progressivamente de 6433 habitantes em 1860 para 18500 habitantes em 1900. Um dos fatores potenciadores deste impulso foi o desenvolvimento da indústria. A instalação da unidade de transformação de cortiça na cidade, pelas mãos de uma família de origem inglesa, contribuiu largamente para as transformações económicas e sociais que se verificaram nesse período.

Em resposta ao Inquérito Industrial de 1881, George Wheelhouse Robinson (1857-1932) indica para a «Fábrica de rolhas de cortiça» de Portalegre um total de 590 operários $^{3}$. 0 número de operários terá variado ao longo dos anos, e neste contexto, mais do que o número exato dos postos de trabalho que a fábrica criou, importa avaliar o alcance daquilo que poderíamos apelidar de universo Robinson e que hoje agrupamos facilmente no conceito espaço Robinson.

10 É comum ler-se em monografias e periódicos locais que os Robinson marcaram de certa forma o quotidiano da cidade. Com a instalação da fábrica na cidade a partir de 1848, os Robinson tornaram-se os principais empregadores da região. Paralelamente, foram responsáveis pela introdução de um conjunto de estruturas até aí inexistentes. Seguindo o legado de seu pai, George William Robinson (1813-1895), George Wheelhouse Robinson empreendeu várias diligências no campo social e cultural: criou um Montepio que tinha como principal objetivo prestar socorro «aos doentes, durante o seu impedimento de trabalhar» (Inquérito Industrial 1881, 63); impulsionou o projeto da creche Batista Rolo (1905) ao ceder o terreno para a sua construção, tendo sido durante algum tempo o presidente da direção desta cooperativa social; criou o Teatro dos Muros, também conhecido como Teatro Recreio Operário (1903), e em 1908 o Corpo de Bombeiros Voluntários Privativos da Robinson. 


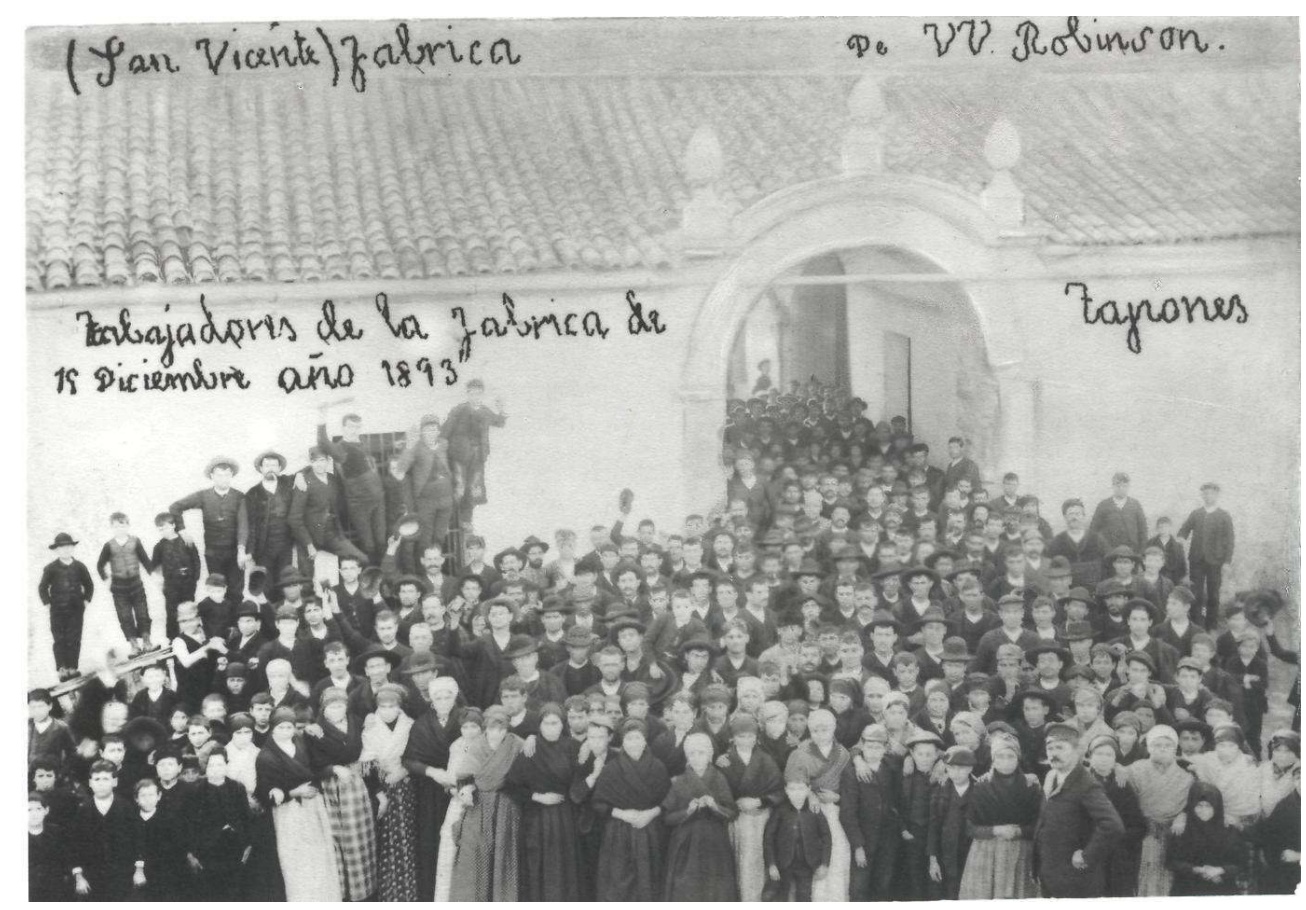

Fig. 1 - Trabalhadores da Fábrica de rolhas de São Vicente de Alcântara, dezembro de 1893 Cortesia de António Ventura

O legado Robinson resulta da conjugação básica dos vestígios de cultura material e imaterial imprescindíveis à sua classificação como património arqueológico industrial. Constate-se as diretrizes intemporais de Febvre $(1977,40)$ : «E, por outro lado, digo os homens. Os homens, únicos objetos da história - de uma história que se inscreve no grupo das disciplinas humanas de todas as ordens e de todos os graus, ao lado da antropologia, da psicologia, da linguística, etc.». Essas exigências de transdisciplinaridade impõem-se como garantia do rigor científico e da objetividade no campo de investigação do projeto em curso. Atendendo a esse posicionamento, importa pois traçar o percurso na investigação que a fundação tem patrocinado, no sentido de contribuir para o registo, estudo, tratamento, divulgação e consequente valorização do património cultural imaterial que a Fábrica Robinson detém.

\title{
Antigos habitantes da Fábrica Robinson
}

\begin{abstract}
«Ouça, depois vinham os homens que às vezes não sabiam bem e andavam à nora para perceber. Uma vez vim para aqui tomar conta disto, da trituração, tive que numerar tudo, os ventiladores, as eclusas (isto tem umas eclusas lá em cima)... Tive que numerar tudo, tudo, tudo, para as pessoas saberem que este circuito é para isto, para aquilo, para outro. E assim sucessivamente, mas mesmo assim havia enganos...» (Cipriano Brito, 2001)
\end{abstract}

Os antigos habitantes são os operários da fábrica, todos os homens e mulheres com quem temos tido a oportunidade e o privilégio de nos cruzar. 0 conceito antigos habitantes ${ }^{5}$ começou a ser utilizado por oposição à designação novos habitantes que define o conjunto das novas realidades arquitetadas para a zona de produção do Aglomerado Branco ${ }^{6}$ destinados às escolas e às associações culturais de Portalegre. Fala-se em novos e velhos para estabelecer diferentes cronologias de ocupação do espaço na evolução da sua função 
industrial aos novos usos que lhe estão destinados nas áreas da cultura, do património e do conhecimento.

O projeto ainda carece em estudos científicos sobre a história do operariado da Fábrica Robinson. Essa lacuna foi em parte colmatada com a antologia periódica editada nas Publicações da Fundação Robinson, que dá conta das movimentações operárias na fábrica entre 1893 e 1920 (veja-se Ventura 2012). Nesta recolha, a história do operariado é feita a partir dos movimentos grevistas e das lutas da classe operária corticeira que contrapõem operários a patrões, como refere Arthur Fontaine sobre o conceito de greve, na procura de uma «melhoria da sua situação material ou na reparação de um dano que (...) consideram como dirigido contra a sua dignidade» (cit. por Ventura 2012, 19). Neste estudo, é possível esboçar um quadro das condições de trabalho do operariado e conhecer alguns aspetos do seu quotidiano laboral. Um estudo aprofundado dos movimentos associativos $^{7}$ que emergiram em Portalegre a partir da segunda metade do século XIX possibilitaria uma incursão pelas sociabilidades e aspetos da cultura e vivência operária em Portalegre, uma vez que estes velhos habitantes já não se podem fazer ouvir.

Para o conhecimento da história e o registo da(s) memórias dos operários de hoje, os que trabalharam na Fábrica até ao seu encerramento em 2009, realizou-se um intensivo trabalho de recolha de campo (entre 2005 e 2011) pelo antropólogo Jorge Murteira: «Neste projeto, inicialmente intitulado "O Operariado e a Fábrica na Cidade", parece-me mais importante assinalar o envolvimento humano (...)» (Murteira 2012, 19). Com a deslocalização da antiga fábrica da sua implantação original e na iminência de se perderem referentes fundamentais para o seu estudo e conhecimento o desafio consistiu na documentação em vídeo dos últimos tempos de laboração da fábrica. Nas palavras de Murteira: «Interessava reter a memória dos operários, a relação com as máquinas, as sociabilidades existentes, quer dentro do espaço fabril, como fora dele» (Murteira 2012, 19). Perante avanços e recuos do projeto resultaram cerca de 60 horas de filmagens, que constituem atualmente um acervo incontornável para o estudo, a preservação e a divulgação dos processos produtivos e dos saberes tecnológicos industriais desta corticeira e das memórias e contextos sociais dos homens e mulheres que ali trabalharam.

De um longo processo de registo resultou o documentário A Ideia Nunca Abala de autoria de Murteira. Forte na sua expressão, (não deixar abalar a ideia que se tem de algo)... ao não deixar partir a(s) sua(s) ideia(s) de fábrica, o documentário narra na primeira pessoa a história de homens e mulheres e de uma parte das suas vidas que se tornou, quase que, as suas vidas, como sugerem os comentários de Fernando Quesada: «O meu pai meteu-me lá a vida inteira! A vida inteira!» e de Ana Maria Trindade: «Nasceram-me lá a que quase que os dentes» (Aqueles que na fábrica habitaram 2012, 8-9).

16 Em todo o processo houve sempre a preocupação em chegar a um número significativo de operários e essa tarefa foi possibilitada primeiramente pelos contactos estabelecidos por Murteira, que resultou numa base de dados que a fundação utiliza amiúde para manter a ligação dos operários ao museu. São convidados para as atividades culturais da fundação, como o dia Robinson ${ }^{8}$, tendo alguns deles participado em ações educativas do museu como intervenientes na realização de visitas guiadas ${ }^{9}$ à fábrica.

17 Atualmente, ao abrigo do Programa Património Ativo ${ }^{10}$ a fundação tem entre os seus colaboradores um antigo operário da Fábrica Robinson. Uma das ideias centrais para o projeto de musealização da fábrica é precisamente poder contar com os velhos habitantes 
da Fábrica Robinson «que todas as coisas conhecem» ... afinal eles também «"novos" habitantes que farão da Fábrica no futuro um Espaço de Cultura» (Gouveia 2012a, 15).

Partindo da base do trabalho de campo antropológico, que privilegiou o contacto direto com a realidade existente a partir da observação e registo, procurou-se estender o nível de compreensão de todo o material recolhido, ao fazer uma antropologia histórica que permitisse compreender melhor os problemas estudados, através de uma abordagem diacrónica e processual (Pereiro 2012,116), privilegiando para o caso as histórias e os relatos de vida que de seguida se apresentam.

\section{Picar o Ponto: conceito e metodologia}

«Quando entrei era miúdo, era tudo sobre rodas»

(Edmundo Catalão, 17 de outubro de 2013)

O contributo dos operários vem dar uma resposta eficaz ao problema de procurar compreender os intricados processos da cadeia operatória na Fábrica Robinson, e como seria de esperar, vem colmatar e esclarecer outros tantos que, entretanto, em discurso direto surgem, como é típico nos projetos em história oral.

Recorrendo à história oral, o objetivo geral é a aproximação e o fomento da relação de proximidade do museu com os antigos operários da fábrica, na senda de anteriores projetos. Como objetivo específico pretende-se valorizar os testemunhos dos operários e evidenciá-los de forma inequívoca na programação do museu, a par do contributo do incremento do corpus documental relativo à fábrica, através de testemunhos orais e localização de documentação na posse dos operários. Como objetivo complementar temos a devolução pública do trabalho realizado, concretizado no próprio programa e de diversas outras formas, como na escrita do presente artigo ou na inclusão da informação a diversos níveis no inventário museológico.

Em Picar o ponto ${ }^{11}$, valoriza-se a voz dos operários e das operárias da Fábrica Robinson, num claro esforço de manter vivos, o mais possível, o património imaterial, a memória de quem habitou anteriormente o espaço Robinson, utilizando as entrevistas e as conversas com os antigos trabalhadores como meio de valorização dos seus percursos pessoais, assumindo, porém, a quebra da transmissão do saber-fazer com o encerramento da fábrica em 2009.

É um projeto com relevância social, na medida em que a história oral é um «(...) meio de manter a experiência passada em estado de presentificação» (Meihy e Holanda 2007, 26), salientando-se a sua urgência devido à idade avançada de alguns dos intervenientes.

O objeto da arqueologia industrial, domínio no qual o Museu Robinson se inscreve, sistematizado por Custódio (1980, 23-27) consiste no inventário, preservação e no estudo do património industrial concretizado em três direções distintas: a arquitetura industrial (os seus materiais, os seus programas funcionais, a sua inserção na paisagem urbana e as suas relações histórico-culturais); as máquinas (a sua compreensão técnica); e a história material da civilização industrial (ritmos e gestos de trabalho, realizações produtivas e a história do acesso aos bens de consumo e de capital), ressaltando assim a complexidade e amplitude do objeto, também abordado por Tinoco e Sousa $(2009,62)$ :

(...) Se o centro de interesse está na Fábrica, monumento por excelência do património industrial, a verdade é que a produção fabril é uma atividade complexa que não pode fazer-se sem energias, instrumentos de trabalho, máquinas, matérias- 
primas e resulta em produtos. O trabalho dos operários é feito por meio de processos tecnológicos. Por outro lado, a montante e a jusante da fábrica há outras instalações e equipamentos que são igualmente objeto do interesse desta disciplina: os bairros operários, pátios e vilas, os armazéns, os escritórios, as gares e os portos com seus equipamentos específicos, os sistemas de abastecimento de água e gás, as centrais termo e hidro-elétricas, as redes rodoviárias, ferroviárias e fluviais, os canais e a própria paisagem modificada pela atividade industrial.

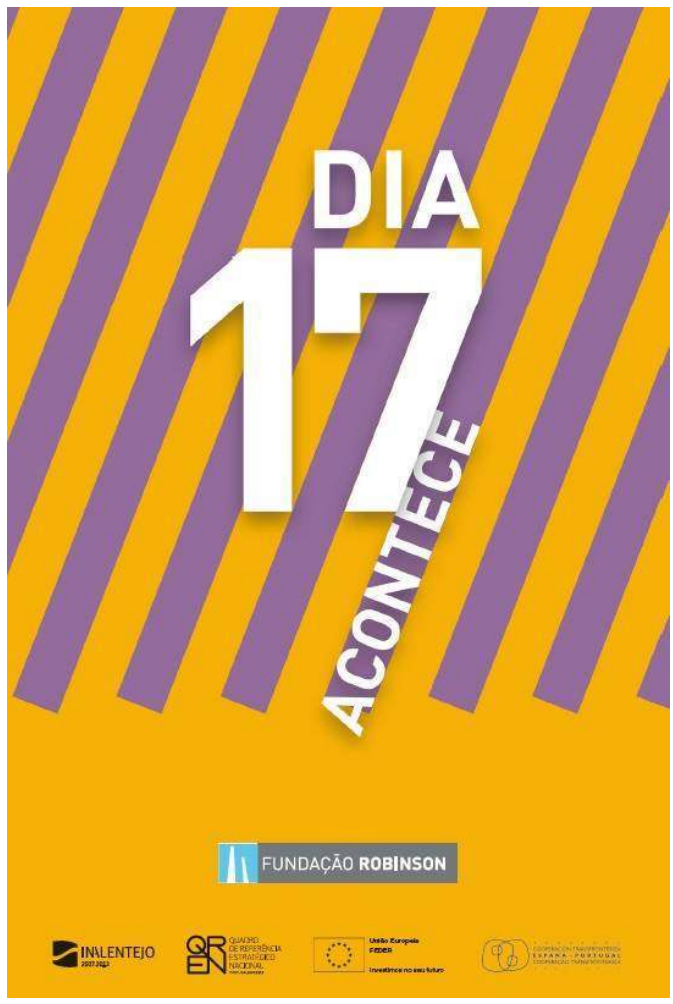

Fig. 2 - Cartaz Dia 17 Acontece (2013), que inclui a atividade Picar o ponto Design TVM designers 


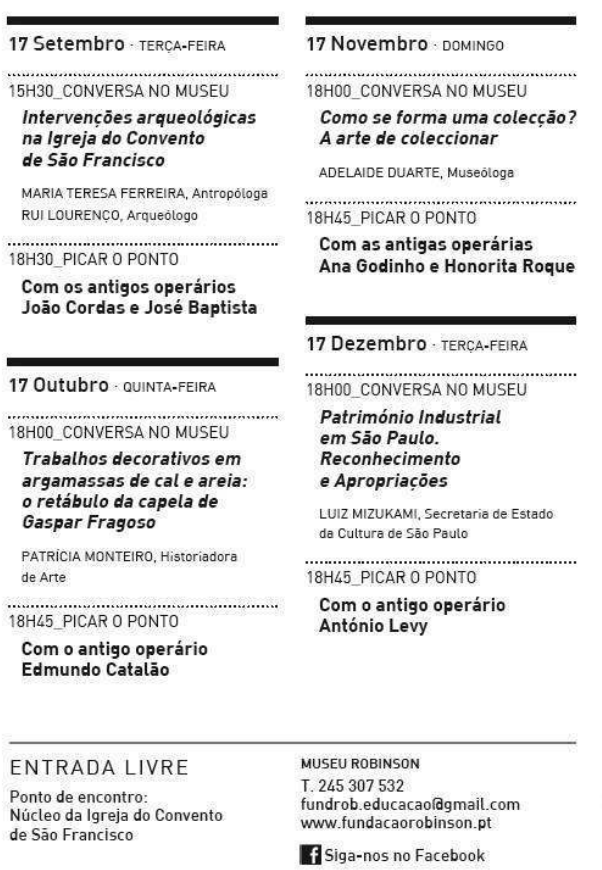

Fig. 3 - Programa Dia 17 Acontece (2013), que inclui a atividade Picar o ponto Design TVM designers com as estratégias e as cartas internacionais de salvaguarda do património industrial, entre elas a Carta de Nizhny Tagil sobre o Património Industrial (2003), que enfatiza a importância das memórias das pessoas que trabalharam em determinado sítio industrial, por constituírem uma fonte única e insubstituível, devendo ser registadas e conservadas, sempre que possível. A carta realça ainda que «o interesse e a dedicação do público pelo património industrial e a apreciação do seu valor constituem os meios mais seguros para assegurar a sua preservação» (TICCIH 2003). Essas preocupações têm sido constantes na atuação da fundação, desde logo no registo em vídeo da fábrica ainda em laboração e da realização de um documentário, entre outras ações, como a presente programação, que pretende afirmar o contributo das memórias individuais e coletivas de diversas gerações de operários para contar a história da Robinson, a partir do estabelecimento de uma relação de igualdade com o discurso de especialistas na área do património cultural.

adotar metodologias da história oral pretende-se conhecer os acontecimentos não «descontaminados», valorizando a subjetividade dos narradores (Cruzeiro 2009, 109). 

pois são elas que garantem a sua existência, vivenciando-o e transmitindo-o às gerações futuras. Como refere Ferreira $(2012,120)$ : «No interior das sociedades industriais e urbanas passamos (...) a encontrar uma clara oposição entre o escrito/formal/objetivo e oral/informal/subjetivo, na forma como os grupos sociais gerem os seus atos de comunicação e a transmissão e fixação do conhecimento», considerando-se, por isso, indispensável a recolha dos testemunhos orais.

A Fundação Robinson já desenvolvia uma base de dados de antigos funcionários e operários da fábrica, que tem sido alimentada constantemente. Foi a partir dessa informação que se fizeram os primeiros convites para o projeto, procurando dar primazia a operários com mais idade e, ainda, conciliar uma diversidade de género e de gerações.

Aplicou-se dentro da metodologia da história oral, o conceito de conversas qualificadas, enquanto fontes orais, num claro esforço de democratização e nivelamento dos sujeitos envolvidos na construção coletiva do conhecimento, procurando dar resposta à necessidade de se ativar e materializar o que existe em estado oral retido na memória dos trabalhadores. Assim, os contactos com os antigos operários têm sido pautados pelos seguintes pressupostos, a partir de Cardin (2009) e de Meihy e Holanda (2007): lugar neutro - disponibilização para encontro em local a combinar com o operário e oferta de possibilidade de encontro no Núcleo da Igreja do Convento de São Francisco e não na antiga fábrica, podendo mais tarde ser completas com visita à fábrica, sempre que desejado pelos interlocutores;

34 - aquisição de um conhecimento prévio do perfil dos sujeitos que compõem o universo de interesse (preparação de breves notas biográficas);

mporta ter presente que em história oral «(...) o indivíduo que rememora ou evoca o tempo vivido, fá-lo sempre de forma seletiva, o que significa que se há lembranças resgatadas, em contrapartida há outras esquecidas e excluídas de forma consciente ou inconsciente» (Cruzeiro 2009, 112).

40 Como sugerem Meihy e Holanda (2007, 26): «É matéria essencial da história oral a humanização das perceções que até então têm sido, geralmente, vistas como expressões institucionais, de macroestruturas, partidos políticos e processos como a industrialização (...)».

41 Tendo em conta as impressões dos antigos operários convidados a participar, decidiu-se não se proceder ao registo fílmico ou sonoro numa primeira fase, tomando-se apenas notas dos relatos obtidos. Essa decisão, pese embora acarretar algumas desvantagens, poderá beneficiar na maior espontaneidade das conversas, a que se quis dar absoluta 
primazia. Foram ainda respeitadas as formas de colaboração pretendidas. Por exemplo, alguns interlocutores solicitaram a participação de um segundo interveniente, num dos casos, um superior, encarregado de seção, noutro caso, de uma colega de trabalho.

As conversas tiveram lugar em diferentes dias, no núcleo da Igreja do Convento de São Francisco e tiveram como objetivo sensibilizar os participantes para a atividade e recolher alguns dados biográfico ${ }^{14}$, mantendo-se para além disso um contato regular com os intervenientes. Ainda que procurando a informalidade e o evitar da predefinição de respostas pelas perguntas formuladas, foi elaborado um protocolo de entrevista para apoio da atividade a partir do trabalho de Parente (2003).

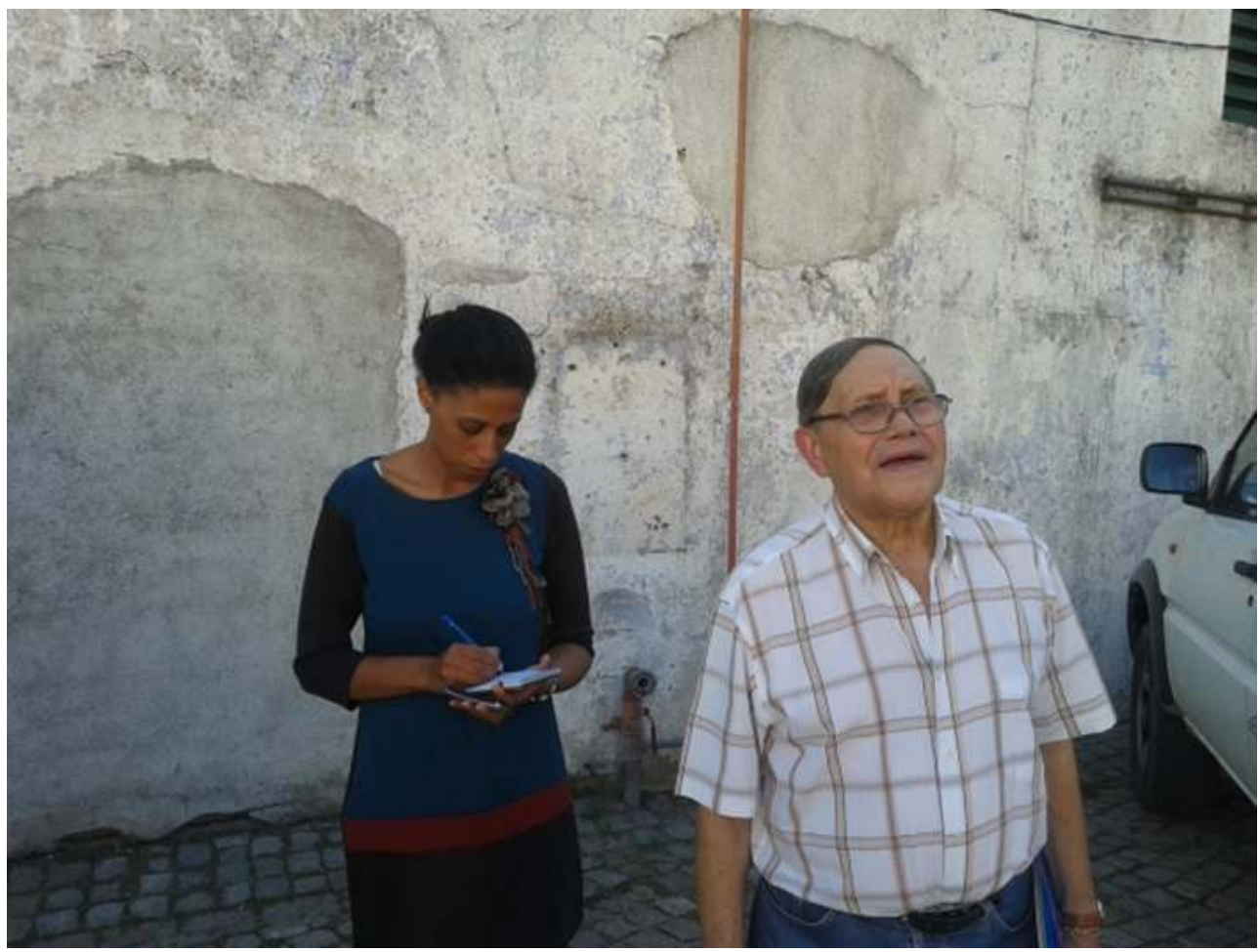

Fig. 4 - Conversa com antigo operário, Edmundo Catalão (n. 1931), durante uma visita à Fábrica Robinson

Fotografia de Roberto Leite @ 2013 Fundação Robinson

Outra metodologia aplicada consistiu no registo e na digitalização de documentação na posse dos operários. Entendeu-se que nesta fase de contactos seria prioritário registar e tomar conhecimento da documentação existente sem, contudo, colocar a possibilidade de doação. Esse pedido, a existir no futuro, será sustentado por uma política de incorporações pensada para o efeito, a partir de um maior grau de proximidade e confiança dos operários com a instituição, relação essa que tem sido sempre fomentada e que se pretende continuar pela sua pertinência, como bem indica Freire (2012, 39): «Será de crucial importância que os antigos operários venham a colaborar no projeto museológico, por exemplo, nas vertentes do inventário, da conservação, da exposição e no serviço educativo.»

O processo documental e de investigação do projeto obedeceu às seguintes etapas metodológicas:

- realização de conversas com os operários; 
47 - recolha de documentação complementar: fotografias, documentos, objetos, disponibilizados pelos operários;

48 - elaboração de uma nota biográfica do operário, com destaque para o percurso na fábrica;

- elaboração de folhas informativas de sala, apresentação em powerpoint com documentação cedida pelo operário para a exibição durante o debate;

50 - divulgação do projeto Picar o ponto, integrado no programa Dia 17 Acontece;

51 - realização da iniciativa Picar o ponto;

52 - registo dos testemunhos e da documentação na base de dados In Patrimonium Premium, programa informático de inventário existente no Museu Robinson.

Deve ainda salientar-se que dada a complexidade sentida por todos os profissionais de museus e de memória em registar e tratar diretamente com fontes orais, que implica o contacto direto com as pessoas, foi necessário uma aturada preparação prévia de todo o processo. Discutido passo a passo em equipa, foi assim traçado um alinhamento para cada conversa, as questões sensíveis a evitar, os cuidados a ter no tratamento e na exposição pública de pessoas não habituadas a falar para uma audiência, sobretudo de questões complexas, sensíveis e pessoais.

Ora, essa preparação foi pensada ao ínfimo detalhe como, por exemplo, a disposição de uma mesa em círculo, de modo a favorecer uma conversa e não um monólogo, a proximidade física com o operário, sempre que necessária ${ }^{15}$, a interrupção e a suspensão de um discurso mais académico ${ }^{16}$ para a transição de um ambiente propício ao diálogo, num registo informal. A preparação de um ambiente mais descontraído foi pensada por meio de uma pausa para café. Estes são exemplos de um cuidado na organização da atividade no sentido de favorecer o conforto e a confiança de quem tem a generosidade de partilhar algo tão importante como a sua vida.

55 Como bem apontou Freire $(2012,40)$ «(...) a história da Fábrica Robinson é apenas um exemplo a par de múltiplas situações semelhantes pelo mundo, em que o rasto deixado é o desemprego». Urge, assim, encetar esforços para dar visibilidade aos operários, com vista a contribuir para «reforçar a necessidade de reintegração destas pessoas na vida económica e cultural da cidade, valorizando efetivamente a sua experiência e os seus saberes especializados.»

56 A recolha dos relatos implica a preparação de um «caderno de anotações» para registar tudo aquilo que não é expresso verbalmente. Como salienta Neto $(2012,28)$ :

o "caderno de anotações" pode ser uma ferramenta de grande auxílio. Ele se movimenta no registo do que não foi dito e tem o papel de documentar atentamente o que não foi declarado, mas que se encontra "colado" às palavras, como os silêncios e os gestos que compõem o conjunto dos relatos na mesma dimensão das entrevistas/testemunhos.

57 Importa ainda sublinhar que é indispensável contar com a colaboração estreita dos antigos operários na explicação do modo de funcionamento do equipamento e de toda a cadeia operatória, a fim de no futuro ser possível devolver esse conhecimento ao público, permitindo ainda alimentar o discurso museológico com valores culturais, sociais e humanos, que facilitarão a interpretação da unidade fabril nas suas complexas ligações de edifícios, espaços, equipamentos, instrumentos e objetos. Um relato vivencial na primeira pessoa, de operários da Robinson, das suas referências e das suas vivências, enriquecido 
ainda com objetos ou documentos que os próprios queiram partilhar, saindo do esquecimento e aproximando-se do espaço do museu, onde um dia poderão regressar.

A implementação de um projeto de envolvimento intergeracional numa região periférica contribui para a afirmação do Museu Robinson enquanto realidade museológica em construção. Portalegre é o único distrito de Portugal que não tem um museu integrado na Rede Portuguesa de Museus. Essa lacuna pode ser contrariada de diversas formas e seguramente são projetos desta natureza, pelo seu caráter descentralizador, integrados em políticas públicas mais abrangentes, que promovem a valorização e qualificação dos espaços museológicos em Portalegre, fomentam a difusão da informação, o rigor profissional e a articulação com outros museus e espaços culturais, desenvolvendo uma maior articulação a nível nacional e internacional.

Este projeto, como já referimos, tem vindo a contribuir para o enriquecimento da documentação relativa à Fábrica Robinson, a par do registo e da recuperação de memórias em permanente transformação que importa fixar para o futuro. Cada testemunho tem um duplo caráter, na medida em que sem perder a sua individualidade inerente, convoca o contexto laboral em que está circunscrito, alargando o seu âmbito para um domínio coletivo.

Pretende-se prosseguir com o projeto de modo a envolver o maior número possível de operários que generosamente queiram partilhar as suas vivências na Robinson o que para muitos equivale a uma vida inteira, reforçando o papel do museu como «(...) um espaço privilegiado para a reflexão sobre as questões sociais ligadas à fábrica e ao seu encerramento.» E fazendo dele «(...) um lugar de encontro, capaz de acolher e reavivar sociabilidades» (Freire 2012, 39).

\section{Picar o ponto com Edmundo Catalão}

61 Edmundo Catalão, 82 anos, saiu da Fábrica há 24 anos, sendo dos operários mais velhos e dos que mais proximamente colabora com o Museu Robinson. Participou na atividade dia 17 de outubro e voltou à Fábrica para contar a sua história, numa conversa aberta na presença de familiares, amigos e público do museu. 0 ambiente gerado na conversa deu azo a que esse momento se transformasse numa homenagem, tendo a imprensa local dado merecido destaque. 


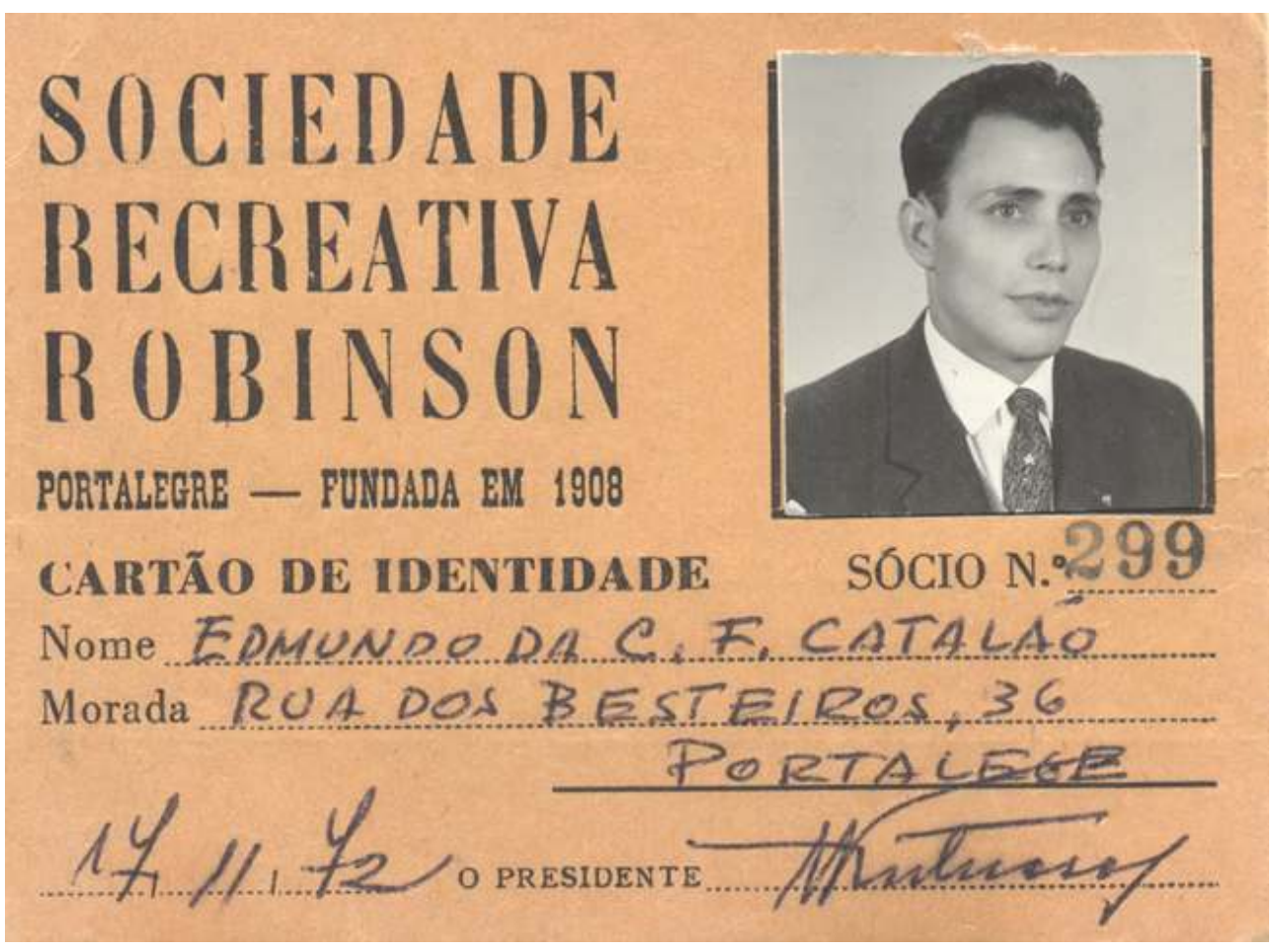

Fig. 5 - Sociedade Recreativa Robinson. Cartão de sócio de Edmundo Catalão, emitido no ano de 1972

Cortesia de Edmundo Catalão (c) Fundação Robinson

62 Começou a trabalhar aos sete anos de idade numa carpintaria, onde continuou até aos 12 anos. Com 14 anos foi trabalhar para a Fábrica Robinson, na chamada prancha, onde, por ter já uma filha, resistiu a "uma grave crise, que reduziu o trabalho na prancha ${ }^{17} \mathrm{e}$ despediu os operários solteiros e sem filhos», passando a trabalhar nas autoclaves ${ }^{18}$ durante 34 anos. Nos seus últimos oito anos de trabalho assumiu o cargo de ajudante de fogueiro, alimentando as caldeiras. Durante mais de três décadas integrou o corpo de bombeiros da Robinson, tendo-se reformando em 1989, aos 58 anos de idade, completando, assim, 44 anos de trabalho na fábrica.

\section{Conclusão}

63 Sendo um projeto, em fase de implementação, os resultados da sua aplicação ainda não foram totalmente estudados e avaliados. No entanto, foi possível anotar aspetos que se figuram como fundamentais para o processo de musealização em curso:

64 - localização e registo de documentação e objetos, bem como instituições que serão potencialmente detentoras de documentação com interesse para a fundação, através de informações fornecidas pelos antigos operários;

65 - registo de documentação cedida para digitalização, entre eles documentos de identificação pessoal, fotografias, ofícios relativos a obtenção de carteira profissional e documentação de preparação para exames para obtenção de carteira profissional, cartões de associações e entidades várias;

66 - diversificação da oferta cultural, com proposta de programação num horário pós laboral, alargando assim a possibilidade de participação a vários segmentos de público. 

ar que assume um caráter obrigatório quando trabalhamos no domínio do património industrial: objetos de grandes dimensões, processos de constituição de coleções industriais, implicando a musealização in situ e problemas específicos de conservação e restauro impõe-no de forma premente. Uma boa solução para minimizar essa complexidade e favorecer a pluralidade é contar com a colaboração estreita daqueles que melhor conhecem a realidade que pretendemos tratar: os antigos trabalhadores.

Contudo, é importante ter presente que o «(...) trabalho da memória cria e recria o passado de forma complexa e, por vezes, contraditória. Encontrando-se associado a um processo de reconstrução, nada é recordado sem ser reconstruído e sem ser evocado a partir do presente (...)» (Ferreira 2012, 119). familiar e da memória do trabalho na construção e organização do relato biográfico, entrecruzando-se estas duas esferas de forma notória, ao evocar-se referências de caráter familiar e marcadores rituais. A aquisição ou alterações de estatuto ou papel social podem ser determinantes no trabalho, como se comprova no relato de Edmundo Catalão que desabafa: «(...) por ter já uma filha, resistiu a "uma grave crise, que reduziu o trabalho na prancha e despediu os operários solteiros e sem filhos".»

81 A ocupação laboral assume grande relevância nos relatos e em todos, sem exceção, foi-nos transmitido com precisão as datas de entrada e saída da fábrica, apontando para um modelo de memória operária com base no espaço fabril discutidos por Halbwachs (1994) e, posteriormente, por Fentress e Wickham (1992). 
género, consubstanciadas nas lutas e conquistas de salários iguais entre homens e mulheres, presente nos relatos das operárias.

Todos os relatos são marcados por um saudosismo dos tempos de laboração da Robinson, havendo tendencialmente nos operários mais velhos, que deixaram a fábrica antes do seu encerramento alguma mitificação e anulação de conflitos, registando-se naqueles que perderam o seu posto de trabalho com o encerramento da fábrica uma profunda mágoa. Em ambos os grupos há, contudo, a consciência de uma degradação e declínio da Robinson ao longo dos últimos anos de laboração.

Os relatos biográficos são pautados pelos aspetos positivos do trabalho, associados a percursos da vida pessoal como a juventude, o casamento, os filhos. Registando-se, ainda, a dureza das condições de trabalho.

Os interlocutores conservam nas suas casas memorabilia sobre o seu percurso na fábrica, desde material de estudo para exames práticos para aquisição de carteira profissional, a fotografias, correspondência diversa, fotografias e amostras de materiais e artesanato produzidos na fábrica. Estes espólios documentais são de relevância extrema, atendendo ao facto de grande parte do espólio documental, por vicissitudes várias, não se encontrar na posse da fundação.

Considerando a multiplicidade de grupos e identidades, importa, como salienta Peralta $(2006,49)$ não nos limitarmos à modelação imposta por um grupo em exclusivo, mas antes assegurar a construção de memórias de forma dinâmica, conflitual e seletiva, apontando para a necessidade de reforçar esta e outras linhas de investigação.

Recuperar a memória dos trabalhadores e do trabalho na fábrica, fomentando o encontro e o debate é uma forma de estimular o envolvimento dos cidadãos, auxiliando-os a gerir a complexa e dura realidade de terem, em muitos casos, perdido o seu emprego, causando uma ferida aberta na cidade de Portalegre. É a forma mais justa de assegurar que no futuro, o Museu Robinson seja capaz de contar a história da fábrica em todas as suas dimensões e que as chaminés da fábrica, verdadeiros ícones de Portalegre, sejam para todos um símbolo do esforço conjunto de uma cidade que se sabe reinventar e prosseguir os seus sonhos, apesar da dureza dos dias.

\section{Agradecimentos}

Os autores agradecem aos operários da Fábrica Robinson que participaram nesta iniciativa: Ana Godinho, António Levy, Edmundo Catalão, Honorita Roque, João Cordas e José Batista.

\section{BIBLIOGRAFIA}

“Aqueles que na Fábrica Habitaram.” 2012. Publicações da Fundação Robinson (22): 6-9. 
Alberto, Jorge Maroco, e Célia Gonçalves Tavares. 2010. "La Fábrica Robinson de Portalegre (Portugal). Rehabilitación y Preservación del Patrimonio Industrial." Llámpara: Patrimonio Industrial (3): 18-27. http://dialnet.unirioja.es/servlet/articulo?codigo=3361981.

Burgess, Robert G. 1997. A Pesquisa de Terreno. Uma Introdução. Oeiras: Celta Editora.

Cabral, Clara Bertrand. 2011. Património Cultural Imaterial: Convenção da UNESCO e Seus Contextos. Lisboa: Edições 70.

Cardin, Eric Gustavo. 2009. "História Oral, Conversas Qualificadas e o Mundo dos Trabalhadores." História na Fronteira. Trabalho e Movimentos Sociais 2 (2): 7-21. http://www.uniamerica.br/site/ revista/index.php/historianafronteira/article/view/78/68.

Carvalho, Ana. 2011. Os Museus e o Património Cultural Imaterial: Estratégias para o Desenvolvimento de Boas Práticas. Vol. 28. Biblioteca - Estudos \& Colóquios. Lisboa: Edições Colibri e Centro Interdisciplinar de História, Culturas e Sociedades da Universidade de Évora.

Costa, Paulo Ferreira da. 2009. Kit de Recolha de Património Imaterial. Lisboa: Instituto dos Museus e da Conservação.

Costa, Paulo Ferreira da, coord. 2009. Museus e Património Imaterial: Agentes, Fronteiras, Identidades. Lisboa: Instituto dos Museus e da Conservação.

Cruzeiro, Maria Manuela. 2009. "História Oral? Dilemas e Perspetivas.” In Cultura: Metodologias e Investigação. 3. Cultura Portuguesa, editado por Maria Manuel Batista, 107-116. Lisboa: Ver o Verso Edições.

Custódio, Jorge. 1980. “Arqueologia Industrial e Património.” História e Crítica (5): 23-27.

Dias, Joana Lino, e Lisete Carrondo, coord. 2008. Fio da Memória. Operários da Fábrica da Pólvora/ Museu da Pólvora Negra. Oeiras: Câmara Municipal, Divisão de Património Histórico e Museológico, Museu da Pólvora Negra.

Febvre, Lucien. 1977. Combates pela História. Tradução de Leonor Martinho Simões e Gisela Monis. Lisboa: Presença.

Fentress, James, e Chris Wickham. 1992. Memória Social. Lisboa: Teorema.

Ferreira, Sónia. 2012. "Memória, Identidade e Género no Seio de uma Comunidade Operária." In Usos da Memória e Práticas do Património, coordenado por Paula Godinho, 119-132. Lisboa: Edições Colibri e Instituto de Estudos de Literatura Tradicional.

Filipe, Graça. 2001. "Perspetivas de Programação e de Funcionamento de Entidades Museológicas com Tutela Municipal Associadas ao Património Industrial.” In I Jornadas de Museologia. O Me Avô Nunca Saía à Rua com a Cabeça Descoberta! São João da Madeira, 155-165. São João da Madeira: Câmara Municipal de São João da Madeira e Museu da Indústria da Chapelaria.

Filipe, Graça. 2003. "Patrimonio Industrial, Experiencias Museológicas y Proyectos de Intervención en el Territorio." In Estructuras y Paisajes Industriales. Proyectos Socioculturales y Turismo Industrial, 79-87. Gijón: Incuna, Asociación de Arqueología.

Freire, Cláudia Jorge. 2012. "Planos de Urgência: Imagens e Sons da Fábrica de Cortiça de Portalegre.” In Publicações da Fundação Robinson (22): 30-41.

Gouveia, António Camões. 2012a. "Para que a Ideia Não Abale.” Publicações da Fundação Robinson (22): 14-17. Portalegre: Fundação Robinson.

Gouveia, António Camões. 2012b. “Práticas de Cultura em Contexto Urbano.” In Cultura Política e Práticas de Cultura, organizado por Carlos Vargas, 131-162. Lisboa: Fonte da Palavra e Observatório Político. 
Halbwachs, Maurice. 1994. Les Cadres Sociaux de la Mémoire. Paris: Albin Michel.

Inquérito industrial. 1881.

Meihy, José Carlos Sebe B., e Fabíola Holanda. 2007. História Oral: Como Fazer, Como Pensar. São Paulo: Editora Contexto.

Mineiro, João. [s.d.]. "Experiências Coletivas, Solidariedades e Identidades: O Caso do Movimento Operário da Covilhã." Ubimuseum - Revista Online do Museu de Lanifícios da Universidade da Beira Interior (2): 139-151. Consultado outubro 18, 2013. http://www.ubimuseum.ubi.pt/n02/docs/ ubimuseum02/ubimuseum02.joao-mineiro.pdf.

Murteira, Jorge. 2012. “Um Caminho Longo para Memória Futura." Publicações da Fundação Robinson (22): 18-25.

Negri, Maximo. 2012. "Industrial Museums." In Industrial Heritage Retooled. The TICCIH Guide to Industrial Heritage Conservation, editado por James Douet, 182-187. Lancaster: Carnigie.

Neto, Regina Beatriz Guimarães. 2012. "Historiografia, Diversidade e História Oral: Questões Metodológicas." In História oral, Desigualdades e Diferenças, organizado por Robson Laverdi et al., 15 -37. Recife: Ed. Universitária da UFPE.

Parente, Cristina. 2003. “Construção Social das Competências Profissionais.” Tese de doutoramento em sociologia, Faculdade de Letras da Universidade do Porto.

Peralta, Elsa. 2006. "Memória Cultural e (re)Imaginação Identitária em Contextos Locais Portugueses." Tese de doutoramento em ciências sociais, especialidade de antropologia cultural, Instituto Superior de Ciências sociais e Políticas.

Pereiro, Xerardo. 2012. Metodologia da Investigação Antropológica. Apontamentos de Antropologia Sociocultural. Universidade de Trás-os-Montes e Alto Douro. Consultado fevereiro 12, 2014. http:// home.utad.pt/ xperez/ficheiros/docencias/manual_de_antropologia_sociocultural_2011_2012/ TEMA\%205\%20\%20ANTROPOLOGIA\%20SOCIOCULTURAL\%202011\%202012.doc.

Portaria n.. 740-DX/2012 de 24 de dezembro, Diário da República, 2. série, n.ํ 248 (2012).

Programa Património Ativo, Portaria n.ำ33/2013, de 29 de janeiro, Diário da República, 1.a série, n.. 20 (2013).

TICCIH (The International Committee for the Conservation of the Industrial Heritage). 2003. Carta de Nizhny Tagil sobre o Património Industrial. The International Committee for the Conservation of the Industrial Heritage. http://www.mnactec.cat/ticcih/pdf/NTagilPortuguese.pdf.

Tinoco, Alfredo, e Élia Sousa. 2009. Património Industrial e Pré-industrial de Montijo: Da Obra à Memória. Montijo: Edições Colibri e Câmara Municipal de Montijo.

UNESCO. 2003. Convenção para a Salvaguarda do Património Cultural Imaterial. Paris: UNESCO.

Ventura, António. 2007. "Para uma Cronologia da Fábrica Robinson: 1848-1966.” Publicações da Fundação Robinson (0): 8-23.

Ventura, António. 2012. “Antologia: Os Conflitos Sociais de Portalegre na Imprensa (1893-1920)." Publicações da Fundação Robinson (23): 34-59.

\section{NOTAS}

1. Reconhecida legalmente desde 2005, a Fundação Robinson foi instituída pela Câmara Municipal de Portalegre e pela Sociedade Corticeira Robinson Bros, S.A. e tem por fim a prossecução de 
atividades de caráter cultural, educativo, social e científico, podendo também agir nas áreas do desporto e da filantropia. Como objetivo específico, a fundação visa a preservação do espólio arqueológico e industrial da Sociedade Corticeira Robinson Bros S.A. e de qualquer outro espólio cuja preservação lhe seja confiada. A sua sede é em Portalegre (Portugal) e a sua ação desenvolvese na região do Norte Alentejano, na Estremadura espanhola e no Reino Unido. A criação de uma instituição capaz de trabalhar para a reabilitação, a valorização, a promoção e a divulgação de todo o espólio da antiga fábrica de cortiça, atualmente património industrial (móvel, imóvel, imaterial), foi entendida como um projeto potenciador no domínio cultural para o concelho de Portalegre, e como uma forma de cooperação, de envolvimento e de motivação das pessoas que, de alguma forma estiveram ligadas à fábrica, garantindo a preservação da identidade e memória local.

2. A Fábrica Robinson foi construída no espaço adstrito à cerca do Convento de São Francisco, na sequência da extinção das ordens religiosas em 1834. A compra de parte do complexo conventual, em 1848, pelo inglês George William Robinson, para a instalação da Fábrica da Rolha, como era conhecida no século XIX, foi determinante para a decisão de se avançar para a recuperação e conservação do património da igreja enquanto espaço conventual. O núcleo da Igreja do Convento de São Francisco encontra-se aberto ao público desde setembro de 2011.

3. Entre os quais: «100 homens; 40 rapazes; 340 mulheres; 80 raparigas» (Inquérito Industrial 1881, 63).

4. Excerto de conversa realizada na Fábrica Robinson com o operário Cipriano Brito (falecido em 2013) a 12 de fevereiro de 2011 no seguimento de um contacto estabelecido com o objetivo de recolher informações sobre o processo de produção do Aglomerado Branco.

5. Termo utilizado na justificação programática do Plano Global de Ocupação e Reabilitação Arquitetónica e Paisagística do conjunto de edifícios e terrenos anexos da Fábrica Robinson.

6. Zona de produção da fábrica para aglomerados para pavimentos (parquet). A designação aglomerado branco está relacionada com a cor do bloco de cortiça após o seu cozimento.

7. Refiram-se os seguintes exemplos: o Montepio Fraternidade Portalegrense (1855); o Montepio Euterpe Portalegrense (1860); a Associação dos Artistas (1866); a Sociedade União Operária (1896); a Cooperativa Operária Portalegrense (1898). A Sociedade União Operária, fundada por George Wheelhouse Robinson e outras personalidades locais, para além da sua função mutualista tinha como objetivos o «recreio, a confraternização, a instrução e a ilustração». A Cooperativa Operária Portalegrense foi fundada por 41 trabalhadores da Fábrica Robinson.

8. Procurou-se, desde logo, na programação da Fundação Robinson, eleger um dia capaz de fixar atenções sobre as dimensões de desempenho humano próximas da fundação. 0 dia 17 de setembro corresponde ao nascimento em Portalegre do primeiro Robinson com dimensão histórica, George Weelhouse Robinson (1857), o grande organizador da firma e o construtor das realidades fabris potenciadoras de produção de qualidade e de riqueza. Em 2013 assinalou-se a sétima edição do dia Robinson.

9. A atividade educativa Encontro de gerações consistiu em visitas guiadas e comentadas à Fábrica Robinson feita por antigos operários a alunos do 1. ciclo. Estes operários colaboraram também na atividade educativa Percursos inserida na exposição temporária Olhares Sincrónicos, que esteve patente no núcleo da Igreja do Convento de São Francisco entre maio e setembro de 2012, que teve como objetivo olhar para a Fábrica Robinson como espaço de inspiração para a criação artística contemporânea.

10. Com a publicação da Portaria n.. 33/2013, de 29 de janeiro, foi criado o Programa Património Ativo, integrando as medidas Estágio-Património (estágios profissionais) e CEI-Património (contratos emprego-Inserção). A Fundação Robinson acolhe desde 24 de junho um grupo de dez beneficiários no âmbito da medida CEI-Património. O trabalho desenvolvido neste âmbito vem suprir uma necessidade há muito sentida pela Fundação Robinson na área da conservação e manutenção do património industrial. 
11. O projeto Picar o ponto foi integrado no programa Dia 17 Acontece proposto numa lógica de promoção de iniciativas de cultura em continuidade, que se repetem todos os dias 17, procurando assim associar um dia do mês a uma programação mensalmente pensada para o Museu Robinson. Foi devidamente assegurado o registo das palestras dos especialistas e dos relatos dos operários que participam no Dia 17 Acontece para organização de um documento no qual estarão resumidas as intervenções de todos os participantes.

12. A propósito do Dia 17 Acontece deve dizer-se que a programação parte da formulação da autoria do Professor Doutor António Camões Gouveia, coordenador científico da Fundação Robinson. Realizando-se todos os dias 17 de cada mês, de setembro a dezembro, pelas 18 horas, a programação de 2013 pretende tornar-se acessível, num horário pós-laboral, ao público em geral. A flutuação dos dias em que se realiza, que pode coincidir com um dia de semana ou com um fim de semana irá naturalmente condicionar a participação de diversos segmentos de públicos, sendo essa uma clara intenção programática.

13. Garantido de imediato, em parte, pelo caráter público das conversas integradas na programação Dia 17 Acontece.

14. Tarefas realizadas entre os meses de julho e agosto de 2013.

15. Deve salientar-se que alguns operários são octogenários, manifestando problemas auditivos.

16. Característico da primeira parte do programa Dia 17 Acontece, com um convidado especialista na área do património cultural.

17. Zona da fábrica destinada ao início do processo de preparação e cozimento da cortiça proveniente dos montados.

18. Linha de doze autoclaves para cozimento dos aglomerados negros de cortiça.

\section{RESUMOS}

Picar o ponto, aludindo a um gesto do quotidiano dos operários, foi o título que de imediato nos surgiu quando se pensou uma atividade para manter viva a ligação aos trabalhadores da Fábrica Robinson, que encerrou as suas portas no início de 2009. Com Picar o ponto o operário regressa à Fábrica... Vem picar o ponto, e traz consigo o que entender necessário para contar a sua história com a fábrica: objetos, fotografias, documentos... ou apenas memórias. Integrado na atual programação do Museu Robinson, com a atividade Dia 17 Acontece, cria-se um espaço para a partilha de experiências pessoais através de relatos biográficos. Pretende-se com esta iniciativa aproximar os cidadãos ao espaço da fábrica, sensibilizando-os para a importância do património industrial, cruzando abordagens de especialistas de várias áreas do património cultural e operários num mesmo espaço-tempo. Num registo de participação pessoal procura-se estreitar laços com os antigos operários enquanto agentes fundamentais para a memória da Fábrica Robinson e como elementos essenciais na construção do projeto para o espaço Robinson em Portalegre, cidade portuguesa do Norte Alentejano com forte tradição industrial.

Picar o ponto (Clocking in, reference to the beginning of a shift in a factory by inserting an individual card in a clock-like device), a gesture repeated by the workers every day, appeared as an obvious title when the Robinson Foundation team decided to conceive an activity to keep alive the link with the workers of Robinson Factory, whose doors closed in early 2009. In Picar o ponto the factory worker returns to the factory and brings along the necessary items to tell the story of his or her time at the factory: objects, photographs, documents... or just memories. Integrated 
within the Robinson Museum programme Dia 17 Acontece, the aim is to create room for exchanging personal experiences through biographical accounts. The intention of this initiative is to bring citizens closer to the factory, alerting them to the importance of industrial heritage, interweaving the approaches of experts from various areas of cultural heritage and those of past factory workers in the same space and time. A record of personal participation, the activity seeks to strengthen ties with former workers as key players of the memory of the Robinson Factory and as essential elements in building the Robinson space in Portalegre, a Portuguese city in Northern Alentejo with a strong industrial tradition.

\section{ÍNDICE}

Palavras-chave: património industrial, património cultural imaterial, Fábrica Robinson, memória, história oral

Keywords: industrial heritage, intangible cultural heritage, Robinson Factory, memory, oral history

\section{AUTORES}

\section{CÉLIA GONÇALVES TAVARES}

Tem licenciatura em História, ramo científico (1999-2003) pela Faculdade de Ciências Sociais e Humanas da Universidade Nova de Lisboa. Na mesma universidade frequentou o curso de pósgraduação no ramo de Formação Educacional (2003-2005) e é atualmente mestranda no curso Práticas Culturais para Municípios. Em 2006 desenvolveu o projeto didático Artes na História na Fundação Eugénio de Almeida e, entre 2004 e 2005, foi professora de história na Escola Secundária do Pinhal Novo. Em 2005 começou a colaborar com a Fundação Robinson, sendo desde 2009 técnica superior nas áreas da história, educação, cultura e património do Museu Robinson. fundrob.cgt@gmail.com

\section{ROBERTO LEITE}

É museólogo. Tem licenciatura em Biologia pela Universidade de Coimbra e uma pós-graduação em Museologia pela Universidade de Évora. Integra a equipa técnica da Fundação Robinson, em Portalegre, desde maio de 2013. Colaborou no projeto de organização e tratamento do arquivo histórico da Comissão Nacional Portuguesa do Conselho Internacional de Museus (ICOM), entre 2012 e 2013. Fez parte da equipa técnica da Rede Portuguesa de Museus de 2006 a 2011. Colaborou com o Museu Botânico da Escola Superior Agrária de Beja (2005-2006), na algoteca do Departamento de Botânica da Universidade de Coimbra (2000-2003) e com o Jardim Botânico da Universidade de Coimbra (1999-2005). fundrob.rdl@gmail.com 